\title{
Construção do saber escolar - gramáticas da primeira infância
}

\author{
Leonor Lopes Fávero" \\ Márcia Antônia Guedes Molina**
}

RESUMO: A instrução primária no Império caminhava a passos lentos na primeira metade do século XIX. Vários projetos eram apresentados, mas só a partir de 1854 a situação começa a mudar, com a reforma Couto Ferraz. A escola primária dividia-se em duas classes, de primeiro e de segundo grau, e tinha um currículo básico que, no primeiro grau, incluía "noções elementares de gramática" o que vai intensificar a publicação, aqui no Brasil, de gramáticas para a primeira infância. A partir de 1870, com o decreto de Leôncio de Carvalho e escudando-se na ideias de Pestalozzi e Froebel, lançase um.novo olhar sobre o aluno e seu processo de aprendizagem. Trata-se da implantação do método intuitivo ou "de lição de coisas", abandonando-se o inglês proposto por Lancaster. É nesse momento histórico que se situa o trabalho, analisando-se duas gramáticas publicadas no período. Entendendo-se o estudo dessas obras como parte da história cultural, observa-se de que forma foram pensadas e escritas. A análise está fundamentada na História das Ideias Lingüísticas no Brasil.

Palavras-chave: Educação primária no Império; método lancasteriano; método intuitivo; gramáticas da primeira infância.

ABSTRACT: Primary instruction during the Empire was making little progress in the
first half of the $19^{\text {th }}$ century. Several projects had been presented with no practical results,
and only from 1854 onwards this situation began to change due to the Couto Ferraz
reform. Elementary schools used to be divided into two sections, primary and secondary,
the basic curriculum of the former including "elementary notions of grammar", which
caused the number of publications of grammar books to go up. From 1870 on, a decree
by Leôncio de Carvalho, which was based on Pestalozzi's and Froebel's ideas, shed
some new light upon students and the learning process. It consisted of the implementation
of the intuitive or "lesson with things" method instead of the one that had been proposed
by Lancaster. This historical moment corresponds to the focus of this paper, in which
two grammar books that were published in that period (1864 and 1886) are analyzed.

USP, UCSP e CNPq.

* UNISA. 
Taking the study of these books as part of cultural history, we look into the way in which they were envisioned and constructed. The analysis is based on the History of Linguistic Ideas.

Keywords: primary instruction during the Empire; the Lancaster method; intuitive method; early childhood grammar books.

\section{A instrução primária no Império}

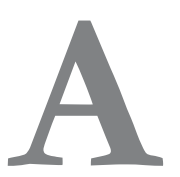

primeira proposta de criação de escolas primárias no Brasil - Projeto Januário da Cunha Barbosa - foi apresentada ao Parlamento em 1826, porém corporificou-se no Decreto de quinze de outubro de 1827 e respondia, de certa forma, ao dispositivo da Constituição de 1824, outorgada por D.Pedro, que garantia instrução primária aos cidadãos brasileiros (excluídos os escravos).

Porém, se o projeto, minucioso e abrangente, explicava o que deveria ser uma escola primária nos moldes europeus, o Decreto, com dezessete artigos, transformava-a em Escola de Primeiras Letras e determinava, em todas as cidades, vilas e lugares populosos, a instalação de escolas elementares, o que, se aplicado, teria dado origem a um sistema nacional de instrução pública, mas isso não ocorreu porque, em 1834, o Ato Adicional transferiu para as províncias o ensino primário e secundário, legalizando a omissão do poder central (Saviani, 2008,p.129) .

Assim, a instrução primária caminhava a passos lentos na primeira metade do século XIX; várias propostas de reforma foram apresentadas com o objetivo de criar um ensino primário na Corte que servisse de modelo às províncias. Coube a Couto Ferraz, Ministro do Império, a tarefa de mudar a situação o que fez pelo Decreto 1331-A de dezessete de fevereiro de 1854 que, apesar de efeitos bastante limitados, atuou como um marco.

No dizer de Saviani (id.,p.132):

Do ângulo das finalidades da escola [a reforma] absorvia a noção iluminista do derramamento das luzes por todos os habitantes do país, o que trazia como corolário: obrigatoriedade aos pais, tutores, curadores ou protetores que tiverem em sua companhia meninos maiores de 7 anos de garantirem o ensino pelo menos de primeiro grau (art. 64), implicando, por conseqüência, a obrigatoriedade, para as crianças, de freqüência às escolas.

Quanto à organização dos estudos, a escola primária dividia-se em duas classes: escolas de primeiro grau e escolas de segundo grau. As primeiras 
tinham um currículo básico que compreendia "a instrução moral e religiosa, a leitura e escrita, as noções essenciais de gramática, os princípios elementares de aritmética, o sistema de pesos e medidas do município" (art.47). Nas escolas de segundo grau acrescentava-se

o desenvolvimento da aritmética em suas aplicações práticas, a leitura explicada dos Evangelhos e notícias da história sagrada, os elementos de história e geografia, principalmente do Brasil, os princípios das ciências físicas e da história natural aplicáveis aos usos da vida.

Quanto aos métodos, na década de 20 utilizava-se o método mútuo ou lancasteriano importado da Inglaterra, em que o professor preparava uma aluno - decurião - que, responsável por grupos de dez alunos,(decúrias), ensinava aos outros. A utilização desse método que gerou muitos debates, estava expressa como exigência no Decreto das Escolas de Primeiras Letras de 1827, mas a imposição não se materializou no Brasil, tendo sido objeto de críticas mesmo em países como a França e a Inglaterra que o utilizaram em larga escala (Bittencourt,1993,p.47-52).

Segundo Fernandes (2006,p.65):

De todo modo, nos mais de 15 anos em que se tentou implementar tal método de ensino no Brasil (é de 1823 a fundação da primeira escola lancasteriana aqui), sua presença ou a discussão sobre ele contribuiu para que, paulatinamente, a sociedade brasileira começasse a enxergar as especificidades da escola e da instrução escolar, segundo suas necessidades de um espaço apropriado, materiais didático-pedagógicos e formação de professores, e não mais nos moldes da educação doméstica nos quais o ensino vinha sendo concebido até então.

Após ele o que se vê nas escolas são métodos mistos, isto é, que procuravam conjugar as vantagens trazidas pelo lancasteriano, com as do ensino individual, mas só a partir de 1870, com a reforma Leôncio de Carvalho, é que se lança um novo olhar sobre o aluno e seu processo de aprendizagem. Trata-se do método intuitivo também conhecido por "lição de coisas”, em que, apoiada pelas ideias de Pestalozzi e Froebel, a escola desvia sua atenção para o aluno:: (...) antes de tudo épreciso aprender a ensinarpara...ensinar a aprender. (Carneiro Leão,1917, p.102).

O crescimento de uma classe média vai acarretar a multiplicação de escolas, tanto primárias quanto secundárias, já que uma das formas de esse segmento diferenciar-se era pela instrução, favorecendo o surgimento de um pequeno mercado editorial, com o lançamento de obras de cunho didático (no caso, gramáticas). Se até então a maioria dessas obras era 
importada de Portugal (a Gramática Elementar de Caldas Aulete, por exemplo, foi aqui largamente utilizada), agora surgem obras escritas por brasileiros e aqui editadas.

Hallewell em sua obra O livro no Brasil (1985, p. 208) mostra que a expansão do sistema educacional viabilizou a produção de livros:
Os últimos vinte anos do Império assistiam a alguma melhora, pelo me- nos quantitativamente, com a duplicação do número de escolas (de 3561 para 7500), e na proporção de escolares relativamente à população (de $1.2 \%$ para $2.1 \%$ ), São Paulo foi suficientemente progressista para tornar o ensino primário obrigatório apenas quatro anos depois da Inglaterra (...) A revolução na educação brasileira começou mais ou menos no últi- mo ano do Império, quando os políticos finalmente tomaram consciência do atraso da nação e a crescente prosperidade do comércio cafeeiro pro- porcionou os recursos necessários, pelo menos no centro e no sul do país.

É nesse momento histórico que se situa o trabalho. Pretende-se discorrer sobre duas gramáticas de Língua Portuguesa adotadas no Brasil, destinadas à infância, a de Joaquim Caetano Fernandes e a de Joaquim Maria Lacerda, analisando - se sua constituição no tocante à morfologia e à sintaxe, para procurar compreender por que teriam elas esse público específico.

Entendendo o estudo dessas obras como parte da história cultural, pretende-se observar de que forma foram pensadas e escritas. Objetiva-se não apenas historiar o passado, mas recuperá-lo, dialogando com o presente. Ao final do texto, mostraremos que, como a história não é um estudo do passado somente, mas uma disciplina que se debruça sobre os homens, as gramáticas surgidas na ocasião, como feitas por e para homens, acabaram por retratar o período em que foram dadas a ler: momento conturbado, de muitas transformações e instabilidade. Apesar disso, o que temos hoje em termos gramaticais é fruto da capacidade de reflexão e observação daqueles pensadores que travaram um constante e profundo diálogo tanto com o seu tempo, quanto com o passado (Fávero e Molina, 2006, p.195), pois, como diz Bakhtin, 1975, p.100):

\footnotetext{
Um enunciado vivo, significativamente surgido em um momento histórico e em um meio social determinado, não pode deixar de tocar em milhares de fios dialógicos vivos, tecidos pela consciência sócio-ideológica em torno do objeto de tal enunciado e de participar ativamente do diálogo social. Do resto, é dele que o enunciado saiu: ele é como sua continuação, sua própria réplica.
} 
A análise está fundamentada na História das Ideias Lingüísticas no Brasil.

2. Gramáticas da Infância ${ }^{1}$

2.1 Gramática da Infância - Joaquim Caetano Fernandes Pinheiro

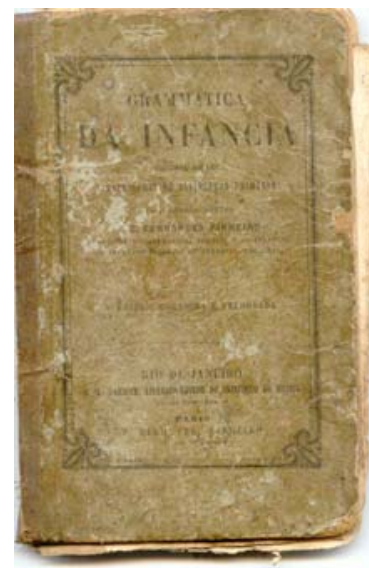

Ilustração 1 - Capa da gramática de J.C.F.Pinheiro

Dados sobre o autor

O cônego Joaquim Caetano Fernandes Pinheiro (1825-1876) lecionou Retórica, Poética e Literatura Nacional no Colégio de Pedro II, foi comendador da Ordem de Cristo e membro dos Institutos Históricos do Brasil e da França, da Academia das Ciências de Lisboa e Madri e da Sociedade Geográfica de Nova Iorque. Polígrafo de compêndios, escreveu, principalmente: Catecismo da Doutrina Cristã (1855), Episódios da bistória pátria contados à infância(1860), Curso Elementar de Literatura Nacional (1862), Meandro Poético (1864), História Sagrada Ilustrada (s/d), Gramática Teórica e Prática da Lingua Portuguesa (com oito edições) e a obra em epígrafe.

Procedemos à atualização ortográfica para facilitar à leitura. 
A obra

Visão geral ${ }^{2}$

A Gramática da Infância, produzida em 1864 e com, pelo menos, quatro edições, é uma pequena gramática de 127 páginas, reunindo um "Aos leitores”, em que o autor explicita que a única coisa que tem na obra feito por si (lembremo-nos que se trata de um compêndio) é o método, já que, afirma, ter procurado simplificar as regras gramaticais. Expressa que espera que sua inovação seja sancionada pela experiência e diz que seu método procura aliar teoria e prática, confiando muito mais nisso do que n'esses arrojos de memória com que alguns preceptores pretender iludir os incautos. (p.1). Trata-se de um compêndio, isto é, obra na qual o autor não tem a pretensão de originalidade, objetivando somente fins didáticos. Segue, a maneira de prefácio, uma peculiar análise de Castro Lopes (professor da Escola Politécnica) acerca da obra. Nesse, Castro Lopes principia discorrendo sobre sua importância e das pessoas que se dedicam às Letras :

$$
\begin{aligned}
& \text { Com efeito, muito pendor, muita dedicação devem ter esses que no Brasil } \\
& \text { em uma época de mercantilismo, e a despeito da grita atordoadora com } \\
& \text { que nos salões de suas orgias a política, nova Mesalina, estraga e corrom- } \\
& \text { pe uma mocidade talentosa, ousam ainda compor livros, escrever com- } \\
& \text { pêndios, e curar da instrução pública. (p.8) }
\end{aligned}
$$

Faz uma digressão nesse momento para criticar subliminarmente a sociedade, em especial, aqueles que se dedicam à política, mas que nada fazem para a Educação:

que esse santo fogo que os anima, e que para arrefecê-lo bastava a indiferença dos governos e a inveja de espíritos tacanhos, acha elementos para seu incremento n'aquele ILUSTRE BRASILEIRO, que ama sinceramente as letras e protege seus sacerdotes.

Voltando a tratar da obra, destaca a importância de uma dirigida à infância, afirmando

... ser repugnante ver meninos e meninas de 7,8 ou 9 anos, estudando tratados gramaticais da língua portuguesa, e carregando inutilmente a cabeça de um acervo ingente de definições metafísicas, que, ingeridas facilmente pela memória voraz da criança, são expelidas pela língua sem jamais se poder fazer a digestão cerebral. (p.9)

A obra estudada é a quarta edição. 
Lembremo-nos aqui de que as criança começava a ser compreendida então como criança, deixando de ser vista como adulto em miniatura.

E A. Castro continua apontando:

Cumpre que o menino aprenda gramática: mas a gramática que deve ser ensinada ao menino não é a mesma que deve aprender o adulto, o que já tem a inteligência desenvolvida pela idade, e mais ou menos enriquecida pelos variados conhecimentos adquiridos.

A sagacidade desse crítico é muito grande. Quando nem se cogitava sobre a importância dos conhecimentos de mundo na compreensão da leitura, faz ele uma afirmação dessa monta.

Depois dessa visão geral, vai, parte a parte, analisando a obra do Cônego, afirmando aqui e ali que cada lição contém um pequeno número de regras, as principais e indispensáveis, relativas ao objeto da mesma lição marcadas com um algarismo. $^{3}$

Continua suas palavras especificando que se sentia feliz sempre que via em obras elementares realizado o princípio de Jacotot com tão feliz artifício aplicado pelo grande Robertson.

J. Jacotot (1770-1840) foi filósofo, matemático, advogado e professor francês criador do método da "emancipação intelectual", baseado em três princípios:

a) todos os homens têm inteligência igual;

b) todos homem recebe de Deus a faculdade de ser capaz de instruir-se;

c) tudo está em tudo.

Afirmava gue o que diferencia os homens é o modo como cada um usa sua inteligência. No que concerne à linguagem, por exemplo, dizia que se deveria oferecer ao estudante uma passagem de poucas linhas, encorajando o aluno a estudar primeiramente as palavras, em seguida as letras, então a gramática, depois o significado, para depois partir para a literatura de um modo geral. Esse seu método está exposto em Enseignement universel, langue maternelle (Louvain and Dijon, 1823) e no Journal de l'émancipation intellectuelle (Achille Guillard, Paris, 1860).

3 Veremos adiante que, ao final de cada tópico gramatical, o autor insere um questionário e exercícios. No primeiro o aluno deveria inserir o número da regra citada acima. 
Parece-nos que, realmente, a tentativa do Cônego foi esta: a de que a criança aprendesse uma coisa de cada vez, então, ao final de cada capítulo, para fixação, apresentava um questionário com perguntas relativas ao conteúdo, cujas respostas deveriam ser localizadas na exposição gramatical e meramente copiadas ipsis litteris, revelando a importância dada na ocasião à memorização do conteúdo. A impressão que se tem é que, para os professores, valia resposta mecânica, sem uma reflexão sobre o assunto. Lembremo-nos de que esse era o método escolástico, "tradicional" que atravessou séculos nas aulas de gramática.

Apesar disso, ao final de cada tópico gramatical, uma grande lista de exercícios, objetivando a retenção do conteúdo, era oferecida aos alunos, talvez também seguindo os ditames de Robertson, cujo método era similar ao de Jacotot, mas aplicado ao aprendizado de uma segunda língua. Esse modelo estimulava o aprendizado na prática, através de atividades, por isso, a cada conteúdo gramatical ensinado uma lista de exercícios era apresentada, cujo tamanho foi crescendo ao longo da obra.

Sobre isso assim se refere o professor da Escola Politécnica:

Os exercícios são excelentes: abundantes de exemplos, em que se verificam as regras pouco antes expressas, além da utilidade prática para o fim gramatical, encerram a vantagem de versarem sobre variadíssimos assuntos, como sejam: história sagrada, história e geografia geral, e principalmente as do país (p.12 - grifos nossos)

Devemos ressaltar que na ocasião do surgimento desse compêndio, aos poucos as obras adotadas deixaram de ser importadas da Europa e, praticamente na mesma ocasião, começaram a ser ensinadas História e Geografia de nossa pátria e a gramática nacional.

Continuando a discorrer sobre a obra, afirma o professor:

De uma atraente amenidade, e adequados a ambos os sexos, há nesses exercícios sentenças. Máximas, reflexões, apotegmas, em suma, proposições, já do próprio autor, já de clássicos portugueses como Vieira, Camões, Bernardim Ribeiro etc. as quais contendo verdades e doutrinas interessantes, é de toda a utilidade implantar no ânimo tenro das crianças.(p.12)

\footnotetext{
As quais, pouco notamos, como verão.

5 Aqui o autor inseria o Futuro de Pretérito e o Imperfeito do Subjuntivo.

6 "Dionísio o Trácio foi o verdadeiro organizador da arte da gramática na Antigüidade" (Neves, 1987, p.155). ou seja, primeiro gramático grego.
} 
Como já se falou, a escola era para meninos (brancos) e as poucas mulheres que frequentavam o ambiente escolar só chegavam às primeiras letras.

Vê-se também que o autor ressalta a formação do caráter, papel, também delegado à escola.

Depois, continuando o prefácio, elogia as modificações introduzidas pelo autor na questão de verbo ${ }^{4}$ e nas cerebrinas classificagões de conjunções copulativas e disjuntivas e a introdução de um novo modo verbal: o modo condicional. ${ }^{5}$

Conclui seu prefácio dizendo que a obra apresentaria, no geral, a doutrina admitida e o que teria de mais importante era o fato de ter sido escrita em estilo e frase a alcance das inteligências infantis, para as quais foi expressamente destinada. (p.14).

Para finalizar a discussão acerca desse prefácio, faz-se importante sublinhar que, ao lê-lo, criamos a expectativa de que estaríamos à frente de uma obra bastante diferenciada das demais, mas não foi isso que constatamos.

Como veremos, ela é seguidora das obras de orientação clássica. Passemos, então, à análise.

O autor inicia discorrendo sobre o conceito de gramática, que, para ele, é uma arte que ensina a declarar bem os nossos pensamentos por meio de palavras. (p.15), dividindo-as em quatro partes, que constituirão as partes da obra.

A definição de gramática como arte remonta à Antigüidade Clássica, Fávero (2001, p.61) ensina:

Ars é tradução do grego. Aristóteles na Metafísica atribui ao termo o sentido de ofício, habilidade para se fazer algo, artesão é o que possui essa habilidade e conhece as coisas pelos efeitos, não pelas causas. Dionísio ${ }^{6}$ chamou sua obra de arte gramatical, por não ser ela especulativa e não prática. (...) A Gramática, a Retórica, a Poética, a Lógica, a Geometria, a Aritmética e a Astronomia são artes; a Matemática e a Física não o são, pois seu objeto é o necessário e elas não são instrumentais. (...)

E, de acordo com a autora, essas sete artes (as praticadas por homens livres, por isso Artes Liberales) constituíram o curriculum escolar durante muitos anos. ${ }^{7}$

7 Muitas dessas disciplinas foram lecionadas por anos sucessivos no Colégio de Pedro II. 
Essa definição atravessou séculos ${ }^{8}$. Nas gramáticas do século anterior, como por exemplo à página VIII da Gramática Filosófica, de Soares Barbosa (publicada em 1822, mas escrita pelo menos duas décadas antes), onde se pode ler: [a gramática] não é outra coisa, [...] senão a Arte, que ensina a pronunciar, escrever e falar corretamente qualquer lingua (..). (grifos do autor).

Continuando, Fernandes Pinheiro, nas pegadas das obras do século XVIII e essas ancoradas nas da Idade Média, divide a gramática em quatro partes: etimologia, sintaxe, prosódia e ortografia:

A divisão em quatro partes, a mesma que se encontra nos gramáticos do século anterior, Reis Lobato e Soares Barbosa [século XVIII] é herança da Idade Média (talvez Prisciano (...)

(Fávero, opus cit, p.65)

Isso se deve, possivelmente à sua bagagem cultural. Já vimos que nasceu no século XVIII. Educado, possivelmente, por religiosos, recebeu formação clássica e chegou, inclusive, a lecionar, além de gramática, filosofia.

Prosseguindo, por etimologia compreende-se a parte que ensina a natureza das palavras e suas propriedades; por sintaxe, a parte que ensina a coordenar com acerto a oração; por prosódia, a que ensina a boa pronunciação das palavras; e por ortografia, a que ensina a escrever sem erros e empregar com acerto os sinais de pontuação. Chamamos atenção para o fato de que, na época, o caráter prescritivo da gramática era o único que havia, ou seja sua função social era ensinar a falar, como dizia Nebrija (1492), de acordo com os nobres:

Cuando bien comigo pienso, mui esclarecida Reina, e pongo delante los ojos el antiguedad de todas las cosas que para nuestra recordación e memoria quedaron escritas, una cosa hallo e saco por conclusión mui certa: que siempre la lengua fue compañera del imperio (p, 6. edição de 1946)

Seguindo ainda a tradição greco-latina, define oração como a reunião de palavras com que enunciamos qualquer juízo. (p.16).

Explica que as palavras que compõem a oração podem ser de dez espécies: substantivo, artigo, adjetivo, pronome, verbo, particípio, preposição, advérbio, conjunção e interjeição. Atentamos aqui para dois fa-

8 Tendo sido abandonada somente no final do século XIX, com o desenvolvimento das ciências em geral e das ciências da linguagem, em especial. 
tos relevantes: de um lado, a proposta de inscrever as classes de palavras em dez categorias remete-nos às dez categorias de pensamento sugeridas por Aristóteles, na Metafísica; de outro, revela modernidade já que as obras do século XVIII, amparadas no modelo latino, desconsideravam o artigo e adjetivo e/ou pronome chegando a oito classes. Notemos que ele já os considera classes gramaticais distintas do nome substantivo, como o fizera anteriormente Pereira Coruja ${ }^{9}$, autor em que parece estar bastante calcado.

Das partes da gramática

Na primeira parte de sua obra, etimologia, chama-nos atenção, primeiramente, o fato de inscrever na classificação dos substantivos comuns, o aumentativo e o diminutivo, revelando não ter muita clareza acerca de flexões (ou derivações). Depois, causou-nos espécie o fato de inscrever alguns pronomes tanto em adjetivos, quanto em pronomes, explicitando:

\footnotetext{
Os pronomes demonstrativos, possessivos, relativos e indefinidos podem ser também adjetivos; e a única diferença que entre eles existe é que quando são adjetivos vêm sempre acompanhados do nome substantivo, e quando são pronomes aparecem sós na oração, ou referindo-se a um nome substantivado oculto (...) (p. 35)
}

Mas especial destaque foi dado por ele ao verbo. $O$ autor assim define esta classe de palavra: Verbo é a palavra que exprime a ação, e serve para ligar o sujeito ao atributo. (p. 56). Acredita serem quatro as conjugações verbais e, como hoje, quatro os auxiliares:ser, estar, ter e haver.

Para ele os modos verbais, como elogiado pelo professor da Escola Politécnica, são cinco: infinito, indicativo, condicional, imperativo e conjuntivo, posição diferente das de seus contemporâneos.

Depois de apresentar a conjugação das terminações verbais (-ar, er, -ir e -or), traz muitas informações a respeito de variações fonéticas notadas em diversas formas verbais, como as dos terminados em -car, -ficar (fico, fique), - cer (conheço, conhece); -gir (exigir, exijo).

Segue a conjugação de diversos verbos irregulares, como dar, estar, crer, dizer, fazer, poder etc. com a indicação, quando é o caso, de quais são seus derivados, ou seja, que os seguem. O verbo pôr é conjugado sepa-

9 Compêndio de Gramática da Língua Nacional. 
radamente sem quaisquer comentários especiais, apenas com a relação das formas que dele foram derivadas.

A discussão da classe de verbos (que ocupa 56 das 122 páginas, portanto, a maior da gramática) é finalizada com um número bastante grande de exercícios, quando o autor começa a tratar dos particípios.

Outra classe de palavra cujo estudo deve ser valorizado aqui é o das conjunções. Para o autor, essa é uma palavra invariável que serve para ligar palavras e oraçoes (p.97), trazendo somente a classificação das que julga principais: copulativas, disjuntivas, condicionais, causais, declarativas, conclusivas e adversativas.

Talvez, pelo fato de a obra destinar-se à infância, tenha preferido relacionar somente as conjunções mais usadas, ao invés de fornecer uma grande relação delas.

A segunda parte de sua obra, sintaxe, rompe, algumas vezes com o postulado por suas antecessoras.

Inicia definindo oração ou período, informando ser a maneira de exprimir qualquer idéia, ou de comunicar aos outros os nossos pensamentos sobre qualquer coisa. (p.103). Depois, afirma que ela (a oração) compõe-se de três partes: sujeito, verbo e atributo, contrariando os preceitos da gramática logicista, como, por exemplo, a de Port-Royal, onde se lê:

(...) como quando digo: A terra é redonda contém necessariamente dois
termos: um chamado sujeito, que é aquele de que se afirma, como terra; e
outro chamado atributo, que é o que se afirma, como redonda, além disso,
a ligação entre esses dois termos, que é propriamente a ação de nosso
espírito, que afirma o atributo do sujeito.
(Arnauld e Lancelot, 1660, trad. de Basseto,e Murachco,1992, p. 85)

Por outro lado, nesta parte da obra, comungando novamente com os preceitos de gramática como arte de falar e escrever bem, traz sintaxe de regência, concordância e construção, seguindo as demais gramáticas de orientação filosófica, como, por exemplo, a de Soares Barbosa (1822). Finaliza o capitulo com sintaxe figurada, estudando as principais figuras de sintaxe.

A terceira e quarta parte da obra que tratam da prosódia e da ortografia, não são objeto de nossa análise.

Importa também especificar que o autor aproveita os exemplos e exercícios para, por meio deles, exercer um outro importante papel que cabia à escola, tão divulgado na época, ou seja, além de ensinar, deveria ela também educar, incutindo nos jovens valores morais. 
(...) no período em questão, houve entrosamento acentuado entre a vida intelectual e as preocupações político-sociais. As diretrizes respectivas conforme as entreviam os nossos homens de então nos modelos franceses e ingleses - se harmonizavam pela confiança na força da razão, considerada tanto como instrumento de ordenação do mundo, quanto como modelo de uma certa arte clássica, abstrata e universal. A isto se juntavam: 1) o culto da natureza, (...) 2) o desejo de investigar o mundo (...)3) finalmente, a aspiração à verdade, como descoberta intelectual, como fidelidade consciente ao natural, como sentimento de justiça na sociedade.

(Candido, 2000:89)

Assim, deparamo-nos, em cada rol de exercícios, ao final dos tópicos gramaticais, com asserções como as que se seguem:

É de nosso dever socorrer os pobres. (p.29)

Jesus Cristo, Senhor Nosso, morreu para nos salvar (p.29)

Leve e suave é a obrigação de obedecermos a nossos pais (31)

Seus dias eram contados por suas virtudes (35)

Ter juízo é a maior de todas as riquezas. (p.45)

Como pudemos observar, a leitura dessa obra fez-nos ver como o homem percebia o mundo, como o representava e era representado por ele.

2.2 Pequena Gramática da Infância composta para uso das Escolas Primárias - Dr. Joaquim Maria de Lacerda

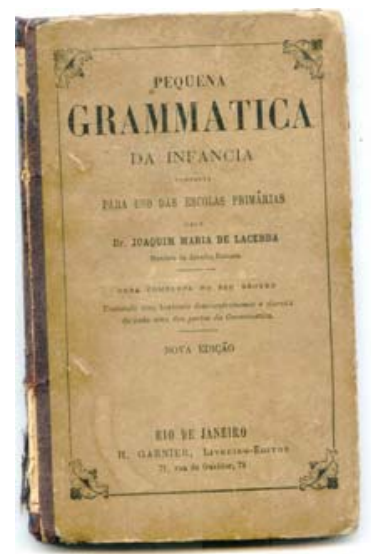

Ilustração 2 - Capa da gramática de Joaquim Maria de Lacerda 
Dados sobre o autor

Joaquim Maria de Lacerda nasceu no Rio de Janeiro em 1838 e morreu em Paris em 1886. Foi professor, membro da Arcádia Romana e autor de inúmeras obras didáticas que continuaram a ser vendidas mesmo depois de sua morte. Dentre suas produções, destacam-se: Alfabeto português, contendo exercícios (1879), Aritmética da infância contendo o sistema métrico decimal, raz̃ões, proporções, regras de três (1881), Aritmética elementar e comercial, contendo todas as operacões da Aritmética e todos os cálculos (s;/d), Compêndio de história sagrada, seguido de uma pequena geografia sagrada $(\mathrm{s} / \mathrm{d})$, tradução do Curso de bistória universal por monsenhor Daniel, bispo de Consances e de Avaranch), Elementos de geografia física, politica e astronomia com estampas coloridas (1870)., Pequena história do Brasil por perguntas e respostas para uso da infância brasileira (1883). Além disso, traduziu o Atlas universal de geografia para uso das escolas e instrução do povo (1883) . Em 1887, atendendo ao Programa de Exames de Fausto Barreto, produz Resumo da corográfica do Brasil, revisto, aumentado e adaptado ao novo programa de exames.

A obra

Visão geral

A Pequena Gramática da Infância para uso das Escolas Primárias não traz a data de sua edição, mas, compreendendo o período de vida do autor, imaginamos que tenha surgido no último quartel do século XIX. A obra consta de um pequeno volume, totalizando 120 páginas e não traz, como se fazia, Prefácio, ou Introducão. É já na Primeira Parte que o autor discorre sobre o conceito de gramática:

Gramática Portuguesa é a arte de falar e escrever corretamente a língua portuguesa - Divide-se em quatro partes, a saber: Etimologia, Sintaxe, Prosódia e Ortografia. (p.1)

- informando, portanto, que ela se divide nas quatro tradicionais partes: Etimologia, Sintaxe, Prosódia e Ortografia, mostrando, dessa forma, seu apego à tradição greco-latina, tanto quanto a obra anteriormente analisada. Chamamos novamente ao texto as palavras de Fávero:

A divisão em quatro partes, a mesma que se encontra nos gramáticos do século anterior, Reis Lobato e Soares Barbosa [século XVIII] é herança da Idade Média (talvez Prisciano (...)

(Fávero, opus cit, p:65) 
Depois, passa a dar as partes da oração, especificando que Oração é o enunciado de um juízo, on as palavras com que se afirma ou nega alguma coisa. (p.2), enumerando dez classes gramaticais: artigo, substantivo, adjetivo, pronome, verbo, particípio, advérbio, preposição, conjunção e interjeição. Novamente é a gramática filosófica inspirando nosso autor.

Oração, ou proposição, ou Frase (pois tudo quer dizer o mesmo) é qualquer juízo do entendimento, expressado com palavras. Ora não sendo qualquer discurso outra coisa senão um juízo, ou uma série deles (...)(Soares Barbosa, 1822, p.363)

Das partes da gramática

Na seqüência começa a discorrer sobre cada uma das classes gramaticais, iniciando pelo artigo. Para o autor, só há, na língua portuguesa, um artigo, o qual tem duas formas: $\boldsymbol{o}, \boldsymbol{a}$, no singular, os, as, no plural, diferentemente do autor anteriormente estudado, que considerava já os artigos indefinidos também.

Ao ensinar substantivos, chamou-nos atenção o fato de, acompanhando novamente a tradição greco-latina, chamá-los de nome e propor sua declinação nos seis casos latinos: nominativo, genitivo, dativo, acusativo, vocativo e ablativo, apresentando a tabelinha parcialmente transcrita a seguir:

Declinação dos nomes com artigos

\section{Singular}

Nom. ó senhor

Voc. Senhor, ó senhor

Gen. Do senhor

Dat. Ao ou para o senhor

Ac. $O$ senhor

Abl. Pelo, do, no, com o senhor

\section{Nome Masculino}

Plural

Ós senhores

Senhores, ó senhores

Dos senhores

Aos ou para os senhores

Os senhores

Pelos, dos, nos, com os senhores

$$
\text { (...) pág. } 6
$$

Ao tratar dos gêneros, inscreve o substantivo nos dois hoje reconhecidos, mas em nota assevera: 
Há gramáticos que admitem um $3^{\circ}$ gênero, o neutro, que é uma forma particular dos adjetivos e de certos pronomes, a qual carece de plural, a qual (sic) carece de plural: v.g. o justo, o injusto, o bom, o mau, o meu, o teu, o sen, isto, isso, aquilo, tudo.(p.5)

Ou seja, a Língua Latina é, para Lacerda, o modelo e a inspiração.

Nenhuma novidade apresenta nos adjetivos, classificando-os, como o antecessor e muitos outros estudiosos de seu tempo em qualificativos e determinativos.

Ao tratar dos pronomes, a definição dada é particularmente digna de ser notada, pois aponta, já naquela época, para sua função textual, como elemento coesivo:

Pronome é uma palavra que se emprega na oração em lugar do nome para evitar a sua repetição. Assim em vez de dizer: Deus apareceu a Abrabão, $e$ disse a Abrahão que em Abrahão seriam abençoadas todas as naçōes, diremos: Deus apareceu a Abrahão e disse-lhe que n'Ele seriam abençoadas todas as nações. (p. 20)

Quanto ao verbo é, para o autor, é a parte da oração que exprime a existência, o estado on a ação do sujeito. V.g. en EXISTO; Pedro DORME; Maria ESTUDA. (p.24). Revela, contudo, seu apego à gramática filosófica, quando em nota esclarece:

Verbo vem do latim verbum, que significa palavra; é a palavra por excelência sem a qual impossível é enunciar um juízo, exprimir um pensamento. V.g. amar, viver, comer, que equivalem a ser amante, ser vivente, estar comendo. (p. 24-25)

- classificando-os em substantivos (os que expressam a existência sem ideia do atributo) e adjetivos (os que expressam conjuntamente a existência e o atributo), uma vez que essa é a mesma divisão apresentada por Arnauld e Lancelot (1660).

Outro fato notório no estudo do verbo é a inserção do supino, dentre os modos verbais, novamente seguindo as pegadas da tradição greco-latina.

Quanto às conjugações, considera três, especificando em notas:

Muitos gramáticos acrescentam a quarta conjugação em -or, que só conta com o verbo pôr e seus compostos. Pode-se porém considerá-lo como um verbo irregular da $2^{\mathrm{a}}$ conjugação, porque a sua forma antiga era poer. (p.30).

Posição antagônica, então, a muitos de seus antecessores, incluindo-se a obra anteriormente analisada. Contudo, considera irregulares os quatro verbos ser, estar, ter, haver hoje em dia analisados como auxiliares, coadu- 
nando-se com o pensamento da maioria dos estudiosos seus predecessores.

Seguem-se modelos e modelos de conjugações verbais, o que faz com que a parte dedicada ao verbo seja a mais extensa da obra, ocupando um quarto de seu total, mostrando mesmo que o autor considera essa classe gramatical a palavra por excelência, como dissemos anteriormente.

Novamente, seguindo a gramática filosófica, aponta ser o particípio uma classe diferente de verbo, explicando: Particípio é uma palavra que participa da natureza do verbo, porque d'ele se deriva; e da natureza do adjetivo, servindo para qualificar os substantivos.(p.28).

No advérbio não apresenta nada de novo e, tanto quanto a obra anterior, traz, no estudo das preposições, uma vasta lista de suas relações. Entretanto, deve-se destacar que, para o autor, conjunção é a palavra invariável que serve para ligar as orações ou diferentes membros de uma frase debaixo de várias relaçōes (p.72), nelas inscrevendo as habitualmente reconhecidas e mais as que chama de continuativas, ou seja, as que servem para continuar ou apoiar o que se acaba de dizer: pois, assim que, ora, com efeito, na verdade, demais, além disso, além de que etc. Recordemonos de que, hoje, na Nomenclatura Gramatical Brasileira, muitas dessas expressões foram colocadas numa "gavetinha", intitulada pelos estudiosos de palauras denotativas, por não haver consenso relativamente a sua classificação.

Finaliza etimologia com a interjeição, explicando: é a palavra invariável que serve para exprimir os sentimentos vivos e súbitos da alma(...) (p.74), calcado, mais uma vez, em Arnauld e Lancelot (opus cit,p.136): As interjeições são igualmente palavras que nada significam fora de nós: são apenas palavras mais naturais que artificiais que indicam os movimentos de nossa alma (...) (grifos nossos).

$\mathrm{Na}$ segunda parte da obra, sintaxe, comungando, mais uma vez, com os preceitos da gramática filosófica, divide os estudos sintáticos em duas partes: sintaxe regular ou natural e figurada e ainda em sintaxe de concordância, sintaxe de regência, sintaxe das orações e de construção. Afirma nosso estudioso:

Oração é um enunciado de juízo ou as palavras com que se afirma ou nega alguma coisa. Uma oração pode ser considerada lógica e gramaticalmente. Considerada logicamente, a oração consta de três partes essenciais: sujeito, verbo e atributo. Considerada gramaticalmente, a oração consta de tantas partes quantas são as palavras que se compõem que são elementos gramaticais. (p.76)

Arnauld e Lancelot (opus cit. p.28) ensinam:

O julgamento que fazemos das coisas quando digo: "A Terra é redonda" se chama PROPOSIÇÃO, e assim, toda proposição encerra necessaria- 
mente dois termos: um chamado sujeito, que é aquilo de que se afirma algo(...) o outro é o atributo (...) além da ligação entre esses dois termos, é.

O autor também navega nas mesmas águas das gramáticas tradicionais, quando define verbo:

Verbo é a palavra que liga o atributo ao sujeito. Todos os verbos, exceto o ser e o estar contêm em si o atributo, pelo que são denominados verbos atributivos ou adjetivos. Assim, amar, viver, existir, comer, equivalem a ser amante, ser vivente, ser existente, estar comendo. Deus está em toda parte, equivale a Deus está presente, está existente em toda parte. (p.77)

Vem a seguir, sintaxe de concordância, regência, orações e construção, sem que houvesse novidades. Notamos, contudo, que muitos dos exemplos fornecidos referem-se aos fatos por que passava nossa pátria, pois o último quartel do século XIX foi um período de muitas mudanças, como a Guerra do Paraguai, movimentos filosóficos como o Liberalismo e o Positivismo que vieram iluminar a República, os migratórios,o início da industrialização etc. Além disso, foi um momento bastante peculiar de consolidação nacional, pois a cada dia mais e mais nos distanciávamos da pátria-mãe. Vejamos como o autor reflete esse tempo em seu texto:

\author{
Este país é magnífico. (p.77) \\ É preciso obedecer às leis. (p.80) \\ O Brasil, cuja fertilidade... (p.81) \\ Os batalhões que partiram... (p.81) \\ O exército dos Paraguaios foi derrotado (p.83) \\ Uma parte das tropas desertou (p.83) \\ O exercício é necessário à saúde (p.85) \\ Obediência às leis é um dever (p.85) \\ O Brasil abunda em riquezas, mas carece de braços (p.86). \\ A paz convém a todos (p.86).
}

Continuando os estudos sintáticos, passa a discorrer sobre sintaxe figurada, que para ele é a composição mais elegante das partes da oração (p.75). Lembremo-nos de que esta obra assenta-se frequentemente sobre critérios filosóficos e, nesse sentido, Aristóteles, informava:

A qualidade basilar da elocução poética consiste na clareza, mas sem trivialidade. Obtém-se a clareza máxima pelo emprego das palavras da linguagem corrente, mas à custa da elevação. Exemplo deste último estilo é 
a poesia de Cleofonte e de Esténelo. A elocução mantém-se nobre e evita a vulgaridade, usando vocábulos peregrinos (chamo peregrinos aos termos dialetais) a metáfora, os alongamentos, em suma tudo o que se afasta da linguagem corrente (Arte Poética, p. 276)

Fornece quatro modos por meio dos quais se pode alterar a regularidade sintática: a) quando se omitem palavras necessárias para completar a oração (ocorrendo isso por elipse, zeugma e silepse); b) quando se acrescentam palavras que poderiam ser omitidas (ocorrendo por pleonasmo); c) quando se substituem ou mudam por outras (ocorrendo por enálage); d) quando se transpõem e se altera a ordem da sua colocação (ocorrendo por hipérbato, anástrofe e tmese).

Seguem-se os vícios de oração, divididos em duas categorias: vícios de construção (solecismo, barbarismo, galicismo, arcaísmo, anfiologia e obscurantismo) e contra a harmonia (hiato, cacófato e eco).

Finaliza esta parte da obra especificando o que é análise, quais os tipos de análise podem ser feitos (gramatical e lógica), exemplos e modelos delas.

A terceira parte de sua obra trata da prosódia, explicando: Prosódia é a parte da gramática que ensina a pronunciar corretamente as palavras com o devido acento e quantidade. (p.105). Continua, apoiando-se no modelo latino: Acento é o tom, ou a maior ou menos elevação de voz com que se pronunciam as sílabas. Quantidade de uma sílaba é o tempo que se gasta na sua pronunciação. (p.105). E, novamente, tomando como base a Língua Latina, explica: As sílabas em relação à sua quantidade são longas, breves e comuns.(p.105).

Depois, dá-nos as Figuras de dição, especificando que se trata de mudanças que se fazem nos vocábulos, sem que se altere sua significação. Dão-se de três maneiras: por acrescentamento (prótese, epêntese, paragoge); por diminuição (aférese, síncope, apócope, sinalefa e ectilipse) e por transposição, ou troca de letras (metástese e antítese). Inclui também as seguintes figuras, sem as relacionar a nenhum dos casos acima: crase, sístole e diástole.

Devemos nos lembrar ainda que a preocupação com a prosódia coaduna-se com as propostas e currículos escolares da época (Colégio Pedro II) aos quais especial atenção era dada à Retórica .

Finaliza o capítulo, diferentemente de seus antecessores, com Breves noções sobre a versificação.

$\mathrm{Na}$ última parte de sua obra Ortografia, explica que essa pode dividir-se em Ortografia das palavras, que ensina a escrever as palavras,e Ortografia do 
para elas direcionados, poucas coisas traziam de diferente dos do Curso Superior. Notamos que todos serviam ao mesmo tempo para ensinar a ler e escrever corretamente nosso idioma e para auxiliar o professor na formação do caráter do educando, inculcando-lhe valores e bons hábitos.

Isto quer dizer que:

Toda obra está ancorada nas práticas e nas instituições do mundo social (...), mas o essencial encontra-se em outra parte, nas relações complexas, sutis, móveis, enlaçadas às formas mesmas das obras (sejam elas simbólicas ou materiais) desigualmente abertas às apropriações, aos costumes e inquietações dos seus diferentes públicos.

(Chartier, 1998, p.9 e 10)

Resta-nos dizer que o nosso empenho foi, então, o de pegar os fios da História, atar com os do Social e descobrir a trama lingüística enredada...

\section{Referênciasbibliográficas}

Fontes primárias

LACERDA, J.M. Pequena Grammatica da Infancia . Rio de Janeiro: H. Garnier, s/d

PINHEIRO, J.C.F. Grammatica da Infancia . Rio de Janeiro: B.L. Garnier, 1864.

Fontes secundárias

ARISTÓTELES. Arte Retórica e Arte Poética. Obra traduzida por Antonio Pinto de Carvalho. São Paulo: Ediouro, s/d.

ARNAULD A. \& LANCELOT, C. Gramática de Port- Royal Gramática Geral e Razoada. Tradução de B. F. Bassetto e H. G. Murachco. São Paulo: Martins Fontes, 1992 [1660]. BARBOSA, J.S. Gramática filosófica da lingua portuguesa. Lisboa: Tipografia da Academia Real das Ciências, 1822.

BAKHTIN, M. Marxismo e filosofia da linguagem. São Paulo: Hucitec, 10ª.ed., 2002 [1975].

BITTENCOURT, C.M.F. Livro didático e conbecimento histórico: uma história do saber escolar. Tese de doutoramento, Universidade de São Paulo, 1993.

CÂNDIDO, A. Literatura e Sociedade. São Paulo: Publifolha, 2000.

CHARTIER, R. A ordem dos livros: leitores, autores e bibliotecas na Europa entre os séculos XIV e XVIII. Trad. de Mary Del Priore. Brasília: Editora UnB, 1998.

FÁVERO, L.L. As concepsões lingüisticas no século XVIII - A gramática portuguesa. Campinas: Editora da Unicamp, 1996.

"Gramática é a arte..”. In: ORLANDI, E.P. (org.) História das Idéias lingüisticas; construção do saber metalingüístico e da constituição da lingua nacional. MT: Unemat Editora, 2001. 
e MOLINA, M.A.G. As concep̣cões lingüísticas no século XIX - a gramática no Brasil. Rio de Janeiro: Lucerna, 2006.

FERNANDES, G. Composição de textos na escola brasileira : em busca de uma bistória. Tese de doutoramento, Universidade de São Paulo, 2006.

HALLEWELL, L. O livro no Brasil. São Paulo: Queiroz editor/EDUSP, 1985.

HOLANDA, S.B. de Raízes do Brasil. São Paulo: Companhia das Letras,: 1999.

LEÃO, A .C. O Brasil e a educação popular. Rio de Janeiro: Tipografia do Jornal do Comércio, 1917.

NEBRIJA, E. A (1492). Gramática castellana. Madrid: Fundación Antonio de Nebrija, 6 ed., 1946.

NEVES, M.H.M. A vertente grega da gramática tradicional. São Paulo: Hucitec, 1987.

SAVIANI, D. História das ideias pedagógicas no Brasil. Campinas: Editores Asociados, 2007. 
discurso que dá as regras da pontuação.(p.114) sem, em momento algum, particularizar a língua 'portuguesa falada no Brasil.

É mister lembrarmos que a ortografia ainda não era normatizada nem em Portugal, nem em nosso país. Em ambos só iriam ocorrer discussões para sua sistematização no início do século $\mathrm{XX}$, mais especialmente em 1904 (Portugal) e 1907 (Brasil), mas urgia que os compêndios escolares tratassem do assunto, já que mais de $80 \%$ da população era analfabeta e mudar essa situação, fazendo a população aprender a ler e escrever, significava a possibilidade de inserção do país no progresso tão almejado. Notemos que essa maneira de pensar ultrapassou séculos, Buarque de Holanda (1999, p.165), apontando que nossa intelectualidade ainda "revela sua missão nitidamente conservadora e senhorial” (p.164) afirma:

(...) É bem característico, para citar um exemplo, o que ocorre com a miragem da alfabetização do povo. Quanta inútil retórica se tem desperdiçado para provar que todos os nossos males ficariam resolvidos de um momento para outro se estivessem amplamente difundidas as escolas primárias e o conhecimento do ABC. Certos simplificadores chegam a sustentar que, se fizéssemos nesse ponto como os Estados Unidos, 'em vinte anos o Brasil estaria alfabetizando e assim ascenderia à posição de Segunda ou terceira grande potência do mundo!'

\section{Considerações finais}

Terminada a análise das obras, julgamos importante relembrar os objetivos desse trabalho: analisar lingüisticamente gramáticas dirigidas à primeira infância utilizadas no Brasil no século XIX e início do XX, por professores particulares, ou por aqueles empregados no chamado Curso Elementar ou Primário, estudando sua partição e conteúdo (disposição, redação e abrangência), delimitando-nos nos conceitos gerais, morfologia e sintaxe (deixando a parte material da língua para um outro momento), Pode-se dizer, de maneira geral, que as gramática estudadas apresentam diferenças das de embasamento puramente filosófico, como as de Jerônimo Soares Barbosa, Moraes Silva e Sotero dos Reis, porque ambas se propunham a analisar a língua entendendo-a como um organismo vivo, fenômeno natural, seguindo as orientações de Darmasteter, Diez e Breal.

Ressaltamos, contudo, que, escritas num período de transição, acabavam apontando características dos dois modelos gramaticais.

Sublinhamos também que os livros para criança, na época, excetuando-se o de João Ribeiro, apesar de apontarem a necessidade de serem 